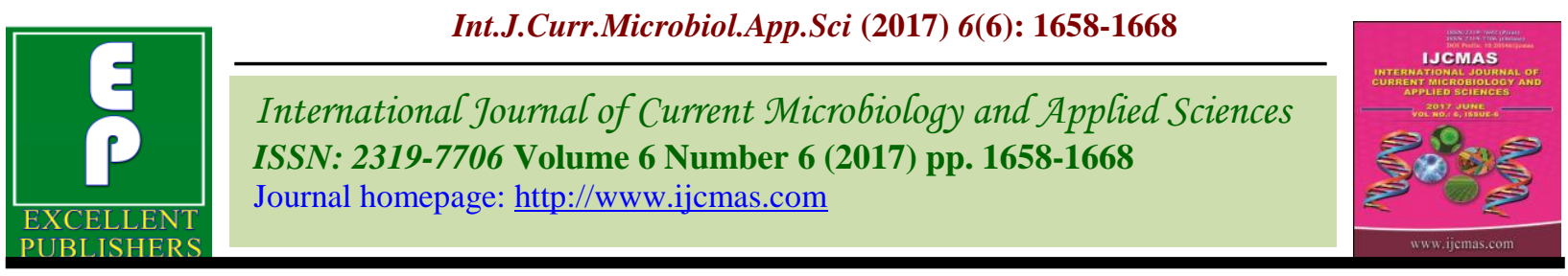

Original Research Article

https://doi.org/10.20546/ijcmas.2017.606.194

\title{
Isolates and their Antibiogram from Blood Stream Infection in a Tertiary Care Hospital, Uttarakannada, India
}

\author{
V.N. Venkatesh* and Swapna Kotian \\ Department of Microbiology Karwar Institute of Medical Sciences, \\ Karwar M. G road Karwar -581301, India \\ *Corresponding author:
}

\begin{tabular}{|c|c|}
\hline & A B S T R A C T \\
\hline & \multirow{8}{*}{$\begin{array}{l}\text { The aim of the work was to study the blood culture isolates and their antibiogram. A total } \\
\text { of } 1070 \text { blood samples were collected from suspected cases of blood stream infection from } \\
\text { August } 2015 \text { to July } 2016 \text {, they were processed aerobically and Antibiogram pattern was } \\
\text { studied. Cultures were positive in } 277(25.89 \%) \text { cases. All the positive cultures were } \\
\text { obtained after } 48 \text { hours of incubation. Gram negative bacteria were } 114(41.16 \%) \text { of the } \\
\text { total isolates with Pseudomonas aeruginosa } 28(10.11 \%) \text { and Gram positive were } 118 \\
(42.60 \%) \text { amongst which coagulase negative Staphylococcus species } 48(17.33 \%) \text { being } \\
\text { the commonest isolate, Candida species isolated in } 46(16.61 \%) \text { of cases. In Gram negative } \\
\text { isolate highest resistance was seen for cefazolin } 63(86.30 \%) \text { followed by aztreonam } 60 \\
(82.19 \%) \text {, amoxicillin + clavulanic acid } 57(78.08 \%) \text { and cefaperazone sulbactum } 53 \\
\text { ( } 72.60 \%) \text { in contrast } S \text {. aureus strains isolated showed highest resistance to cotrimoxazole } \\
40 \text { (93.02\%) followed by penicillin } 29(67.44 \%) \text { and erythromycin } 27(62.79 \%) \text {. Blood } \\
\text { cultures provide a valuable guide in identifying etiological agent and selecting appropriate } \\
\text { antibiotic. Thus helps to achieve a high level antibiotic activity against the off ending } \\
\text { bacterial organism. }\end{array}$} \\
\hline Keywords & \\
\hline $\begin{array}{l}\text { Bloodstream } \\
\text { infection, } \\
\text { Isolates, } \\
\text { Antibiogram. }\end{array}$ & \\
\hline Article Info & \\
\hline $\begin{array}{l}\text { Accepted: } \\
23 \text { May } 2017\end{array}$ & \\
\hline Available Online: & \\
\hline 10 June 2017 & \\
\hline & \\
\hline
\end{tabular}

\section{Introduction}

Blood stream infection is the most common health care associated infection and an important cause of mortality and morbidity around the globe (Diekma et al., 2003). The illness associated with the infection may range from mild self limiting to life threatening sepsis requiring rapid and aggressive antimicrobial treatment (Young et al., 1995). Blood stream infection may be transient bacteraemia which is an indication of true systemic infection or contamination from skin (Ladhani et al., 2004; Ayoola et al., 2002). Microbiological culture of blood remains gold standard for the diagnosis of bacterial agents and antibiotic susceptibility providing essential information for the evaluation of broad range of diseases like endocarditis, pneumonia, pyrexia of unknown origin and helpful particularly in patients with suspected sepsis allowing for successful recovery of bacteria in $99 \%$ patients with bacteraemia (Yagupsky et al., 1990). Antimicrobial resistance is growing threat worldwide in health care setting and possesses a major risk for human health. Resistance to antibiotics limits the success in therapy and prevention of disease (Dagnachew et al., 2014; Singh et al., 2013; 
Opintan et al., 2015). Among the resistance shown Extended Spectrum Beta lactamase (ESBL) producing enterobacteriacea pose a major threat among drug resistant bacteria (Paterson et al., 2005). Keeping all these facts in view the present study was carried out with aim to determine the microbial profile of blood stream infection and their Antibiogram to different antibiotics, which would enable determination of empiric antimicrobial strategies guiding in infection control and rational use of antibiotics in this region.

\section{Materials and Methods}

The present study was carried out from August 2015 to July 2016 in the Department of Microbiology Karwar Institute of Medical Sciences Hospital, Karwar. After the approval from Institutional Ethical Committee and obtaining a written informed consent from the patients, a total of 1070 samples were collected from suspected cases of blood stream infection from patients belonging to all the age groups with detailed history. Antibiotic usage empirically before or after admission was noted. Blood samples from culture were collected following aseptic precautions. The venous site was cleaned with $70 \%$ alcohol and with allowing it to dry for 12 minutes, asset of two samples were collected giving a hour interval from different anatomical sites. The collected blood was inoculated into blood culture bottles containing Brain Heart Infusion broth (BHI) with $0.025 \%$ of Sodium polyanethol sulphonate as anticoagulant (Himedia, a commercial firm).

The blood culture bottles were then incubated $37^{\circ} \mathrm{C}$ aerobically. After overnight incubation, the bottles were observed for turbidity and broths were subcultured with aseptic precautions onto blood agar, Mac Conkey agar and Chocolate agar. The plates were incubated at $37^{\circ} \mathrm{C}$ overnight. If there was no growth observed on the plates the next day, the samples were further incubated and subsequently subcultured till seventh day. If growth was observed it was identified based on gram staining, colony characteristics and standard bio chemical tests (Elmer et al., 2006). Antibiotic susceptibility test were performed against locally available antibiotics by using disk diffusion methods in accordance with Clinical and Laboratory Standards Institute (CLSI) criteria (Clinical and Laboratory Standards Institute, 2007).

Drug resistant strains belonging to gram negative bacilli (GNB) oxidase negative were studied for Extended Spectrum BetaLactamases (ESBL) by double disk diffusion test that is by enhancement of the inhibitory zone between clavulanate impregnated disk Augmentin (Amoxicillin 20- Clavulanic $10 \mu \mathrm{g})$ and disk impregnated with Cefotaxime $(30 \mu \mathrm{g})$ placed $20 \mathrm{~mm}$ apart (centre to centre). To check for Methicillin resistant S. aureus

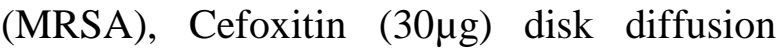
method was used. Escherichia coli ATCC 25922, Klebsiella oxytoca ATCC 700324, Pseudomonas aeruginosa ATCC 27853, S. aureus ATCC 25923 and Enterococcus fecalis ATCC 29212 were included as control strains.

Statistical analysis was done manually. Qualitative variables were expressed as percentages and the culture reports were issued.

\section{Results and Discussion}

During the study period a total of 1070 blood culture samples were collected among which $672(62.80 \%)$ were males and 408 (38.13\%) were females as seen in table 1 . Of these 1070 samples a positivity of $159(57.40 \%)$ was seen in males and 118 (42.60\%) was seen in females as depicted in table 2. Out of the 277 positive samples $114(41.16 \%)$ were GNB 
which include E. coli 25 (9.03\%), K. pneumoniae 24(8.66\%), Salmonella species 13 (4.69\%), Acinetobacter species 12 (1.44\%), K. oxytoca 8 (2.89\%), Enterobacter species $4(1.44 \%)$ and $P$. aeruginosa 28 (10.11\%). Among Gram Positive Cocci (GPC) isolated CoNS 48 (17.33\%), S. aureus 43 (15.52\%), Enterococcus species 19 $(6.86 \%)$ and Micrococcus 8 (2.89\%). In addition 46 Candida species (16.61\%) were isolated as seen in table 2.

Highest blood culture positivity was seen in 0 -10 years age group cases with $234(84.48 \%)$ positivity out of total 277 cases. Among the GNB Pseudomonas aeruginosa 28 (11.97\%) followed by Klebsiella pneumoniae 20 $(8.55 \%)$ was the commonest isolate and in GPC CoNS 44(18.80\%) followed by MSSA $43(18.38 \%)$ were the commonest isolates. 13 $(4.70 \%)$ isolate were from 11-20 years age group with Salmonella species 5(38.46\%) being the commonest isolate followed by $E$. coli $4(30.77 \%)$ and Acinetobacter species 4 (30.77\%). 10 cases $(3.61 \%)$ were from $41-50$ years age group with E. coli $6(60 \%)$ being the commonest isolate. 21-30 years had 8 $(2.89 \%)$ positive case with Salmonella species $8(100 \%)$ being isolated. 7 cases $(2.35 \%)$ belonged to 31-40 years with E. coli $7(100 \%)$ being isolated as seen in table 3 .

S. aureus strains isolated showed highest resistance to Cotrimoxazole $40 \quad(93.02 \%)$ followed by Penicillin 29(67.44\%) and Erythromycin 27(62.79\%). All the strains of $S$. aureus isolated were sensitive to Cefoxitin as seen in table 4. Of the 19 strains of Enterococcus highest resistance was observed for Cotrimoxazole 13(68.42\%) followed by Erythromycin $12(63.16 \%)$ and for Penicillin $11(57.89 \%)$ and Ticarcillin Clavulanic acid $11(5.89 \%)$.

Gram negative bacilli oxidase negative showed $100 \%$ sensitivity to Polymyxin B 300 and Colistin. Highest resistance was seen for Cefazolin $63 \quad(86.30 \%)$ followed by Aztreonam 60 (82.19\%), Amoxicillin Clavulanic acid 57 (78.08\%), Cefaperazone sulbactum 53 (72.60\%). The most sensitive antibiotic was Meropenem $4(5.48 \%)$ as observed in table 6. 19 (26.03\%) of the total GNB isolates were found to be Extended Spectrum Beta Lactamase producer. Among 28 Pseudomonas aeruginosa isolated 100\% sensitivity was seen for Polymyxin B and Colistin. Highest Resistance was seen for Cefaperasone - Sulbactum 20(71.43\%), Ceftazidime 13(46.43\%) and Cefepime $13(46.43 \%)$. Least resistance was observed for Amikacin 1(3.57\%) and Meropenem 1(3.57\%) table 7. Of the 13 Salmonella species isolated highest resistance was observed for Ciprofloxacin $6(42.86 \%)$ and Ceftazidime $5(38.46 \%)$ as seen in table 8 .

Changing trend in microbiology, epidemiology of the infecting agent and the clinical and prognostic significance of bacteraemia has been observed over the last 20 years. The timely detection of bacteraemia can have a profound influence on the clinical outcome (Aranson et al., 1987). The study demonstrates the microbial isolate distribution causing bacteraemia and their susceptibility pattern to the most commonly used oral and parentral antimicrobial agents. In our study, a total of $277(25.89 \%)$ isolates were identified which is in accordance with few previously conducted studies by Qureshi et al., (2011), Ravi et al., (2012) and Jambo et al., (2010). This is quite low compared to studies conducted by Jain et al., where a positivity of 52. 63\% was noted (Roy et al., 2002). The reason for low rate in our study could be due to prior empirical antibiotic treatment before the collection of sample for the culture resulting in negative cultures. The other reason for low rate could be due to infection by anaerobic organisms which cannot be detected by routine aerobic culture. 
The most common age group showing positive culture was 0 - 10 years group with $234(84.48 \%)$ positivity among which 213 $(91.03 \%)$ were neonates as this group is most vulnerable for infection due to their developmental status and physical examination findings are less reliable in neonates (Elbashier et al., 1998; Berkley et al., 2005; Berger et al., 1998). They are vulnerable to infection because of their weak immunological barriers. Lack of infection control procedures, inadequate sterilization of multiuse instruments, understaffing and crowded nurseries in developing country provide means for transmission of neonatal infections (Stapleton et al., 2015). Higher incidence in children were also quoted by other studies (Murty et al., 2007).

Predominance of gram positive organism was seen in comparison to gram negative bacilli. Recent reports too have shown that gram positive organisms particularly the cocci are assuming greater significance in causing bacteraemia concomitant with increasing incidence of nosocomial blood stream infection. Such change happened parallel to the evolution of medical care, more so with increasing number of critically ill and immune compromised individuals who require aggressive medical support and indwelling devices. A total of $118(42.60 \%)$ belonged to the Gram Positive Cocci group with the highest isolation of MSCoNS $48(17.33 \%)$, CoNS previously considered as a contaminant is being recognised increasingly as a cause of bacteraemia. The ascendance of this group of Staphylococci has created increased interpretative difficulties for the clinicians since great majority of CoNS isolates continues to represent contamination rather than true bacteraemia as it is a common skin habitant and may indeed contaminate poorly collected blood cultures leading to difficulty in determining bacteraemia from contamination (Robert et al., 1991; Weinstein et al., 1997; Behrman et al., 2004; Naas et al., 2016). In our study 48(17.33\%) was isolated which is similar to the rate of isolation in studies conducted by Tariq Mahamud (2014) showing $26.34 \%$ and by Murthy et al., $25 \%$ but is low when compared to studies conducted by $\mathrm{T}$ Naas et al., (30) showing a positivity of $54.76 \%$ and Hanan et al., (2005) having $55.4 \%$ rate of isolation. Haini Chen et al., have suggested qualitative culture to aid interpretation and determine vascular relation (2002).

S. aureus was isolated in $43(15.52 \%)$ while in some of the other studies by Bernadette et al., 5.7\%, Atul garg et al., 8.3\% (2007), Hanan et al., 9.5\% (2005) and Tariq Mahmud $26.34 \%$ (2014) showed a varying rate of isolation. Friedland et al., reported in $36 \%$ of children having Staphylococcal septicemia had silent endocarditis and some cases of "no focus' could be related to cardiac lesions and according to one study it was seen that $57 \%$ of cases where $S$. aureus was repeatedly isolated will have a cardiac pathology and all such patients with $S$. aureus bacteraemia should be thoroughly evaluated for the presence of any cardiac pathology as the cardiac vegetation serves as important source of persistent $S$. aureus bacteraemia. Enterococcus species was isolated in 19 $(6.86 \%)$ cases and it was reported earlier that Enterococcal BSI is more common in older age group with instrumentation and prior to or with antimicrobial therapy (Madani et al., 1999).

E. coli is the most common enterobacteriacea causing gram negative bacteraemia as see in other studies but our study revealed Klebsiella species as the predominant etiological agent. Klebsiella species has been isolated as the main etiological agent in many other studies conducted by Tariq Mahmud 16.10\% (2014), Nass et al., 27.5\% (2016), Alaah Al et al., $46.8 \%$ (2005) and DS Murthy 35\% (2007). 
The resistance of Klebsiella species to antimicrobials may be an essential factor in their higher emergence in nosocomial infection (Alaa et al., 2005).

In the recent years increased incidence of systemic fu gal infection especially by Candida species has been noted in hospitalised intensive care unit patients. With an increased use of broad spectrum antimicrobials, endotracheal tubing, invasive lines in these patients it is known to be easy for Candida to bypass the natural barriers of infection and contribute to deep seated infection. Maternal factors also contribute to septicaemias. In the present study Candida species was isolated in 46(16.61\%).
Antifungal susceptibility testing was not done due to lack of facilities. S. aureus as found to be resistant to many antibiotics with highest resistance to Cotrimoxazole $93.02 \%$ followed by Penicillin $67.44 \%$, Erythromycin $62.79 \%$, Amoxicillin Clavulanic acid $55.81 \%$ and Linezolid 19 (44.19\%). Similar resistance pattern have also been seen in studies conducted previously by Bibek Bhatt et al., (2015), Atul Garg et al., (2007) and Roy et al., (2002). Enterococcus species was highly resistant to Cotrimoxazole in $13(68.42 \%)$, Erythromycin 12(63.16\%), Penicillin 11(57.87\%), Ticarcillin Clavulanic acid $11(57.89 \%)$ and Amikacin 8(42.11\%), Clindamycin $8(42.11 \%)$, Teicoplanin 8 (42.11\%).

Table.1 Gender distribution

\begin{tabular}{|l|l|l|l|}
\hline & Positive $(\mathrm{n}=277)$ & Negative & Total $(\mathrm{n}=1070)$ \\
\hline Male & $159(57.40 \%)$ & 520 & $672(62.80 \%)$ \\
\hline Female & $118(42.60 \%)$ & 296 & $408(38.13 \%)$ \\
\hline Total & 277 & 816 & 1070 \\
\hline
\end{tabular}

Table.2 Spectrum of isolates

\begin{tabular}{|c|l|}
\hline Isolates & Number $(\%)(\mathbf{n}=\mathbf{2 7 7})$ \\
\hline Gram Negative Bacilli & \\
\hline 1. Pseudomonas aeruginosa & $28(10.11 \%)$ \\
\hline 2. Escherichia coli & $25(9.03 \%)$ \\
\hline 3. Klebsiella pneumoniae & $24(8.66 \%)$ \\
\hline 4. Salmonella species & $13(4.69 \%)$ \\
\hline 5. Acinetobacter species & $12(4.33 \%)$ \\
\hline 6. Klebsiella oxytoca & $8(2.89 \%)$ \\
\hline 7. Enterobacter species & $4(1.44 \%)$ \\
\hline Gram Positive Bacilli & \\
\hline 1. Staphylococcus aureus & $43(15.52 \%)$ \\
\hline 2. Coagulase Negative & $48(17.33 \%)$ \\
\hline Staphylococcus species & \\
\hline 4. Enterococcus species & $19(6.86 \%)$ \\
\hline Fungal isolate & $8(2.89 \%)$ \\
\hline 1. Candida species & \\
\hline Total & $46(16.61 \%)$ \\
\hline
\end{tabular}


Table.3 Nutritive value of ripe mango per 100g Age wise distribution

\begin{tabular}{|c|c|c|c|c|c|c|c|c|c|c|c|c|c|}
\hline $\begin{array}{l}\text { Age in } \\
\text { years }\end{array}$ & 1 & 2 & 3 & 4 & 5 & 6 & 7 & 8 & 9 & 10 & 11 & 12 & Total \\
\hline $0-10$ & 8 & 20 & 12 & 4 & 0 & 8 & 28 & 43 & 44 & 8 & 19 & 40 & 234 \\
\hline $11-20$ & 4 & 0 & 0 & 0 & 5 & 4 & 0 & 0 & 0 & 0 & 0 & 0 & 13 \\
\hline 21-30 & 0 & 0 & 0 & 0 & 8 & 0 & 0 & 0 & 0 & 0 & 0 & 0 & 8 \\
\hline $31-40$ & 7 & 0 & 0 & 0 & 0 & 0 & 0 & 0 & 0 & 0 & 0 & 0 & 7 \\
\hline $41-50$ & 6 & 0 & 0 & 0 & 0 & 0 & 0 & 0 & 4 & 0 & 0 & 0 & 10 \\
\hline $51-60$ & 0 & 0 & 0 & 0 & 0 & 0 & 0 & 0 & 0 & 0 & 0 & 5 & 5 \\
\hline$>60$ & 0 & 0 & 0 & 0 & 0 & 0 & 0 & 0 & 0 & 0 & 0 & 0 & 0 \\
\hline Total & 25 & 20 & 12 & 4 & 13 & 12 & 28 & 43 & 48 & 8 & 19 & 45 & 277 \\
\hline $\begin{array}{l}\text { 1- Esche } \\
\text { 2-Kleb } \\
3-\text { Kleb } \\
\text { 4- Enter } \\
\text { 5- Salmo }\end{array}$ & $\begin{array}{l}\text { acc } \\
\text { a pn } \\
\text { ox } \\
\text { ter } \\
\text { a sp }\end{array}$ & $\begin{array}{l}\text { onia } \\
\text { a } \\
\text { ies }\end{array}$ & 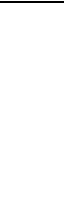 & $\begin{array}{l}\text { 6- } A \\
7-P \\
8-\mathrm{N} \\
9-\mathrm{N} \\
10-1\end{array}$ & $\begin{array}{l}\text { etob } \\
\text { dom } \\
\text { A } \\
\text { CoN } \\
\text { roco }\end{array}$ & ter sh & $\begin{array}{l}\text { cies } \\
\text { cies } \\
\text { cies }\end{array}$ & 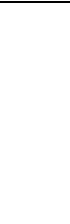 & $\begin{array}{l}11-E n \\
12-C\end{array}$ & $\begin{array}{l}\text { roco } \\
\text { dido }\end{array}$ & $\begin{array}{l}\text { s spe } \\
\text { ecies }\end{array}$ & & \\
\hline
\end{tabular}

Table.4 Resistance pattern of Staphylococcus aureus

\begin{tabular}{|c|l|l|}
\hline Sl. No & Antibiotic & Number $(\%)(\mathbf{n}=\mathbf{4 3})$ \\
\hline 1. & Cotrimoxazole & $40(93.02 \%)$ \\
\hline 2. & Penicillin & $29(67.44 \%)$ \\
\hline 3. & Erythromycin & $27(62.79 \%)$ \\
\hline 4. & Amoxicillin - Clavulanic & $24(55.81 \%)$ \\
\hline 5. & Linezolid & $19(44.19 \%)$ \\
\hline 6. & Ciprofloxacin & $16(37.21 \%)$ \\
\hline 7. & Teicoplanin & $11(25.58 \%)$ \\
\hline 8. & Vancomycin & $8(18.60 \%)$ \\
\hline 9. & Amikacin & $8(18.60 \%)$ \\
\hline 10. & Chloramphenicol & $8(18.60 \%)$ \\
\hline 11. & Clindamycin & $8(18.60 \%)$ \\
\hline 12. & Gentamicin & $5(11.63 \%)$ \\
\hline 13. & Rifampacin & $4(9.30 \%)$ \\
\hline
\end{tabular}

Table.5 Resistance pattern of Enterococcus species

\begin{tabular}{|r|l|l|}
\hline Sl.No & Antibiotics & Number $(\%)(\mathbf{n = 1 9})$ \\
\hline 1. & Cotrimoxazole & $13(68.42 \%)$ \\
\hline 2. & Erythromycin & $12(63.16 \%)$ \\
\hline 3. & Ticarcillin - Clavulanic & $11(57.89 \%)$ \\
\hline 4. & Penicillin & $11(57.89 \%)$ \\
\hline 5. & Amikacin & $8(42.11 \%)$ \\
\hline 6. & Clindamycin & $8(42.11 \%)$ \\
\hline 7. & Teicoplanin & $8(42.11 \%)$ \\
\hline 8. & Rifampacin & $5(62.32 \%)$ \\
\hline 9. & High level Gentamicin & 0 \\
\hline 10. & Vancomycin & 0 \\
\hline
\end{tabular}


Table.6 Resistance pattern of Enterobacteriacea (Oxidase Negative )

\begin{tabular}{|r|l|l|}
\hline Sl.No & Antibiotic & Number $(\mathbf{\%})(\mathbf{N}=\mathbf{7 3})$ \\
\hline 1. & Cefazolin & $63(86.30 \%)$ \\
\hline 2. & Aztreonam & $60(82.19 \%)$ \\
\hline 3. & Cefuroxime & $59(80.82 \%)$ \\
\hline 4. & Amoxicillin -Clavulanic acid & $57(78.08 \%)$ \\
\hline 5. & Cefotaxime & $56(76.71 \%)$ \\
\hline 6. & Cefaperazone - sulbactum & $53(72.60 \%)$ \\
\hline 7. & Ticarcillin Clavulanic acid & $53(72.60 \%)$ \\
\hline 8. & Cefepime & $52(71.23 \%)$ \\
\hline 9. & Gentamicin & $47(64.38 \%)$ \\
\hline 10. & Piperacillin Tazobactum & $40(54.79)$ \\
\hline 11. & Cotrimoxazole & $36(49.32 \%)$ \\
\hline 12. & Ciprofloxacin & $17(23.29 \%)$ \\
\hline 13. & Amikacin & $13(17.81 \%)$ \\
\hline 14. & Meropenem & $4(5.48 \%)$ \\
\hline 15. & Polymyxin B & Nil \\
\hline 16. & Colistin & Nil \\
\hline
\end{tabular}

Table.7 Resistance pattern of Pseudomonas aeruginosa

\begin{tabular}{|c|l|l|}
\hline Sl.No & Antibiotic & Number $(\mathbf{\%})(\mathbf{n = 2 8})$ \\
\hline 1. & Cefaperazone sulbactum & $20(71.43 \%)$ \\
\hline 2. & Ceftazidime & $13(46.43 \%)$ \\
\hline 3. & Cefepime & $13(46.43 \%)$ \\
\hline 4. & Piperacillin Tazobactum & $8(28.57 \%)$ \\
\hline 5. & Ticarcillin - Clavulanic acid & $7(25 \%)$ \\
\hline 6. & Aztreonam & $6(21.43 \%)$ \\
\hline 7. & Gentamicin & $5(17.86 \%)$ \\
\hline 8. & Cotrimoxazole & $3(10.71 \%)$ \\
\hline 9. & Ciprofloxacin & $2(7.14 \%)$ \\
\hline 10. & Amikacin & $1(3.57 \%)$ \\
\hline 11. & Meropenem & $1(3.57 \%)$ \\
\hline 12. & Polymyxin B & Nil \\
\hline 13. & Colistin & Nil \\
\hline
\end{tabular}

Table.8 Resistance pattern of Salmonella species

\begin{tabular}{|r|l|l|}
\hline Sl.No & Antibiotic & Number $(\%)(\mathbf{n}=13)$ \\
\hline 1. & Ciprofloxacin & $6(42.86 \%)$ \\
\hline 2. & Ceftazidime & $5(38.46 \%)$ \\
\hline 3. & Cefazolin & $4(30.77 \%)$ \\
\hline 4. & Cefotaxime & $4(30.77 \%)$ \\
\hline 5. & Clindamycin & $4(30.77 \%)$ \\
\hline 6. & Aztreonam & $3(23.08 \%)$ \\
\hline 7. & Chloramphenicol & Nil \\
\hline 8. & Cotrimoxazole & Nil \\
\hline 9. & Meropenem & Nil \\
\hline 10. & Azithromycin & Nil \\
\hline
\end{tabular}


A combination of third generation Cephalosporin with Aminoglycosides have been usually considered from Gram negative bacteraemia but in the recent days it was seen that at least $60-70 \%$ of the gram negative organisms are resistant to most of these antibiotics (Mehta et al., 2005). In the present study among the various antibiotics used for the susceptibility testing for gram Negative oxidase negative organisms resistance was seen for many antibiotics in varying percentage with least resistance to Meropenem 4 (5.48\%) and Ciprofloxacin $(23.29 \%)$ and Cotrimoxazole 36 (49.32\%). For oxidase positive bacilli least resistance was observed for Amikacin 1 (3.57\%), Meropenem 1 (3.57\%), Ciprofloxacin 2 $(7.14 \%)$ and Cotrimoxazole $3(10.71 \%)$.

ESBL producing enterobacteriacea have become well recognised in many hospitals worldwide. The extended spectrum beta lactamase enzyme showing plasmid mediated resistance as a consequence of point mutation in the TEM or SHV gene represents a widening threat to the utility of the antimicrobials (Canton et al., 2008; Shukla et al., 2004; Paterson et al., 2005; Nwadioha et al., 2010). These ESBL producing GNB's were also known to be multidrug resistant and show high resistance to commonly used anti microbials like Ampicillin, Gentamicin, third generation Cephalosporin and Fluroquionolones. Previous studies have suggested that in patients with serious infection due to Ceftazidime resistance third generation cephalosporin's could not be used. The lack of data in patients undergoing therapy with combination of beta lactam plus a beta lactamase inhibitor limits their usage and concomitant resistance to ciprofloxacin restricts empiric use of these agents in circumstances when an extended spectrum beta lactamase producing organism is suspected (Schiappa et al., 1996). For antimicrobials like Penicillin,
Cephalosporin's, aminoglycosides in enterobacteriacea and Pseudomonas aeruginosa resistance was seen based on decreased entry of drugs (Bhatta et al., 2015).

In conclusion, blood stream infection is an important cause of morbidity and mortality in our patients. Klebsiella species, E. coli, $P$. aeruginosa and Staphylococcus species remain the principal bacteria responsible for infection. Blood cultures provide a valuable guide to the clinician in identifying etiological agent and selecting appropriate antibiotic. There should be an effective and rational use of antibiotic especially in tender age group in order to achieve a high level antibiotic activity against the offending bacterial organism.

\section{References}

Alaa, H., Al-Charrakh, Ali, M. Al-Muhana, Zainab, H. Al-Saadi. Bacterial Profile of Blood Stream Infections In Children Less Than Three Years Old. J. Babylon Univ., 10(3): 481-485.

Aranson, M.D., Bor, D.H. 1987. Diagnostic decisions: Blood cultures. Ann. Intern. Med., 106: 246-53.

Atul Garg, S., Anupurba, Jaya Garg, R.K., Goyal, M.R. Sen. 2007. Bacteriological Profile and Antimicrobial Resistance of Blood Culture Isolates from a University Hospital. J. Indian Acad. Clin. Med., 8(2): 139-43.

Aube, H., Milan, C., Blettery, B. 1992. Risk factors for septic shock in the early management of bacteremia. Am. J. Med., 93: 283-288.

Ayoola, O.O., Adebowale, A., Adeyemo, A. and Osinusi, K. 2002. Predictors of bacteraemia among febrile infants in Ibadan, Nigeria. J. Health Popul. Nutr., 20: 223-229.

Bates, D., Pruess, K., Lee, T. 1995. How bad are bacteremia and sepsis: outcomes in 
a cohort with suspected bacteremia. Arch. Intern. Med., 155: 593-598.

Behrman, R., Kliegman, R., Jenson, H. 2004. Nelson Textbook of Pediatrics.17th Edition. Philadelphia: Saunders.

Berger, A., Salzer, H., Weninger, M., Sageder, B., Aspock, C. 1998. Septicaemia in an Austrian neonatal intensive care unit: a 7-year analysis. Acta Paed., 87: 1066-1069.

Berkley, J.A., Lowe, B.S., Mwangi, I., Williams, T., Bauni, E., Mwarumba, S., et al. 2005. Bacteremia among children admitted to a rural hospital in Kenya. $N$. Engl. J. Med., 352: 39-47.

Bhatta, B., Thapa, R., Shahi, S., Karki, S., Bhatta, Y., Das, J.K., Pandeya, DR. 2015. Isolates and their Antibiogram in Different Samples from a Tertiary Care Hospital, Kathmandu. Med. J. Shree Birendra Hospital, 14(1): 1-8.

Canton, R., Novais, A., Valverde, A., Machado, E., Peixe, L., Baquero, F., et al. 2008. Prevalence and spread of extended spectrum betalactamase producing Enterobacteriaceae in Europe. Clin. Microbiol. Infect., 14: 144-53.

Clinical and Laboratory Standards Institute. 2007. Performance standards for antimicrobial susceptibility testing. Pennsylvania: Clinical and Laboratory Standards Institute.

Collignon, P., Nimmo, G.R., Gottlieb, T., and Gosbell, L.B. 2005. Staphylococcus aureus bacteraemia, Australia. Emerging Infect. Dis., 11: 554-561.

Dagnachew, M., Yitayih, W., Getachew, F., Tesfaye, N., Kasaw, A., Belete, B., et al., 2014. Bacterial isolates and their antibiotic susceptibility patterns among patients with pus and/or wound discharge at Gondar university hospital. BMC Res. Notes, 7: 619.

Diekma, D.J., Beekman, S.E., Chapin, K.C., et al., 2003. Epidemiology and outcome of nosocomial and community onset bloodstream infection. J. Clin. Microbiol., 41: 3655-60.

Elbashier, A.M., Malik, A.G., Khot, A.P. 1998. Blood stream infections: microorganisms, risk factors and mortality rate in Qatif central hospital. Ann Saudi Med., 18: 176-180.

Elmer, W., Koneman. 2006. Koneman's color atlas and Text book of Diagnostic Microbiology. $6^{\text {th }}$ Edition. Philadelphia: Lippincott Williams and Wilkins.

Friedland, I.R., du Plessis, J., Cilliers, A. 1995. Cardiac complications in children with Staphylococcus aureus bacteremia. J. Ped., 127: 746-748.

Haimi-Cohen, Y., Vellozzi, E.M., and Rubin, L.G. 2002. Initial concentration of Staphylococcus epidermidis in simulated pediatric blood cultures correlates with time to positive results with the automated, continuously monitored BACTEC blood culture system. J. Clin. Microbiol., 40: 898901.

Hanan, A., Babay, Kingsley Twum-Danso, Abdelmageed, M., Kambal, Fawzia, E. Al-Otaibi. 2005. Blood stream infection in pediatric patients. Saudi Med. J., 26(10): 1555-1561.

Jambo, G.T.A. 2010. Microbial isolates from clinical specimens of blood culture and their antimicrobial susceptibility profiles: Findings from an analysis of 3,255 blood culture specimens at a university teaching hospital in Southern Nigeria. Int. J. Biol. Med. Res., 1: 6670.

Ladhani, S., Konana, O.S., Mwarumba, S., English, M.C. 2004. Bacteraemia due to Staphylococcus aureus. Arch. Dis. Child, 89: 568-571.

Madani, T.A.A., Kabani, A., Orr, P., Nicolle, L. 1999. Enterococcal bacteremia in a tertiary care centre in Winnipeg. Infect. Dis. Med. Microbiol., 10: 57-63. 
Mehta, M., Priya Dutta, P., Gupta, V. 2005. Antimicrobial susceptibility in blood infection from teaching hospital, India. J. Infect. Dis., 58: 174-6.

Murty, D.S., M. Gyaneshwari. Blood cultures in pediatric patients: A study of clinical impact. Indian J. Med. Microbiol., 25(3): 220-4.

Naas, T., Cuzon, G., Robinson, A.L., Andrianirina, Z., Imber, P., Ratsima, T., et al. Neonatal infections with multi drug resistant ESBL-producing E. cloacae and $K$. pneumoniae in Neonatal Units of two different Hospitals in Antananarivo, Madagascar. Bio Med. Central Infect. Dis., 16: 275-284.

Nwadioha, S.I., Nwokedi, E.O.P., Kashibu, E., Odimayo, M.S., Okwori, E.E. A review of bacterial isolates in blood cultures of children with suspected septicemia in a Nigerian tertiary Hospital. African J. Microbiol. Res., 4(4): 222-225.

Opintan, J.A., Newman, M.J., Arhin, R.E., Donkar, E.S., Gyansa-Lutterodt, M., Mills-Pappue, W. 2015. Laboratory based nationwide surveillance of antmicrobial resistance in Ghana. Inf. Drug Resistance, 8: 379-389.

Paterson, D.L., Bonomo, R.A. 2005. Extended-spectrum beta-lactamases: a clinical update. Clin. Microbiol. Rev., 18: 657-86.

Paterson, D.L., Bonomo, R.A. 2005. Extended-spectrum b-lactamases: a clinical update. Clin. Microbiol. Rev., 18: 657-86.

Qureshi, M., Aziz, F. 2011. Prevalence of microbial isolates in blood cultures and their antimicrobial susceptibility profiles. Biomedica, 27: 136-9.

Rani, N.V., Gopal, K., Narendra, M.V., Vishwakanth, D., Nagesh, V.R., Yogitha, M., et al. 2012. A retrospective study on blood stream infections and antibiotic susceptibility patterns in a tertiary care teaching hospital. Int. J. Pharm. Pharmaceut. Sci., 4: 258-65.

Regalario, B.R., Alinea, M.C.D. 2012. Antibiotic Prescribing Patterns of Pediatric Residents: Do the Results of Blood Cultures Make a Difference? PIDSP, 13(1): 51-56.

Robert, F.J., Geere, I.W., Coldman, A. 1991. A three year study of positive blood cultures with emphasis on prognosis. Reviews Infect. Dis., 13: 34-46.

Roy, I., Jain, A,. Kumar, M., Aggarwal, S.K. 2002. Bacteriology of neonatal septicemia in a tertiary care hospital of Northern India. Indian J. Med. Microbiol., 20: 156-9.

Schiappa, D.A., Hayden, M.K., Matushek, M.G., Hashemi, F.N., Sullivan, J., Smith, K.Y., Miyashiro, D., et al. 1996. Ceftazidime-Resistant Klebsiella pneumoniae and Escherichia coli Bloodstream Infection: A Case-Control and Molecular Epidemiologic Investigation. The J. Infect. Dis., 174: 529-36.

Shukla, I., Tiwari, R., Agrawal, M. 2004. Prevalence of extended spectrum blactamase producing Klebsiella pneumoniae in a tertiary care hospital. Indian J. Med. Microbiol., 22: 87-91.

Singh, S., Khare, M., Patidar, R.K., Bagde, S., Sahare, K.N., Dwivedi, D., Singh, V. 2013. Antibacterial Activities Against Pyogenic Pathogens. Int. J. Pharm. Sci., Res., 4(8): 2974-2979.

Stapleton, P.J., Murphy, M., McCallion, N., Brennan, M., Cunney, R., Drew, R.J. Outbreaks of extended spectrum betalactamase-producing Enterobacteriaceae in neonatal intensive care units: a systematic review. Arch. Dis. Child Fetal Neonatal., 101: 72-8.

Tariq, M.T. 2014. Bacteriologic Profile and Antibiogram of Blood Culture Isolates from a Children's Hospital in Kabul. $J$. 
College of Physicians and Surgeons Pak., 24(6): 396-399.

Wagner, G.E. 1990. Bacteraemia and septicemia. In: kingsbury, D.T., and Wagner. G.E.(eds.) Microbiology. 2nd edition. John Wiely \& Sons. Inc., USA. pp.315-320.

Weems, J., Jr. 2002. The many faces of Staphylococcus aureus infection. Postgrad. Med., 3: 33-41.

Weinstein, M.P., Towns, M.L., Quartey, S.M., Mirrett, S., Reimer, L.G., Parmigiani, G., et al. 1991. The clinical significance of positive blood cultures in the 1990s: a prospective comprehensive evaluation of the microbiology, epidemiology, and outcomes of bacteremia and fungemia in adults. Clin Infect. Dis., 24: 584-602.

Yagupsky, P., Nolte, F.S.1990. Quantitative aspects of septicemia. Clin. Microbiol. Rev., 3: 269-79.

Young, L.S. 1995. Sepsis syndrome. In: Mandell GL, Bennett JE, Dolin R, eds. Principle and Practice of Infectious Dis., Churchill Livingstone, 690-705.

\section{How to cite this article:}

Venkatesh, V.N., and Swapna Kotian. 2017. Isolates and their Antibiogram from Blood Stream Infection in a Tertiary Care Hospital, Uttarakannada. Int.J.Curr.Microbiol.App.Sci. 6(5): 16581668. doi: https://doi.org/10.20546/ijcmas.2017.606.194 